\title{
New approaches for mitral valve surgery without opening the left atrium
}

\author{
Jeffrey Shuhaiber ${ }^{1}$, Marcos Nores $^{2}$ \\ ${ }^{1}$ Wellman Institute for Photomedicine, Massachusetts General Hospital, Wellman Institute, Boston, MA, USA; ${ }^{2}$ JFK Medical Center, Atlantis, FL, USA \\ Correspondence to: Jeffrey Shuhaiber, MD. Massachusetts General Hospital, Wellman Institute, Thier Bldg, 50 Blossom St., Boston, MA 02114, USA. \\ Email: Jeffrey.Shuhaiber@gmail.com. \\ Provenance and Peer Review: This article was commissioned by the Editorial Office, fournal of Thoracic Disease. The article did not undergo external \\ peer review. \\ Comment on: Li J, Gu C. Off-pump mitral valve repair: primary result of treating moderate ischemic mitral regurgitation during off-pump coronary \\ artery bypass grafting. J Thorac Dis 2019;11:3191-4.
}

Submitted Nov 26, 2019. Accepted for publication Dec 13, 2019.

doi: $10.21037 /$ jtd.2019.12.78

View this article at: http://dx.doi.org/10.21037/jtd.2019.12.78

From the turn of this century and beginnings of treating the mitral valve prior to the era of the heart-lung machine, surgeon pioneers such as Drs. Cuttler, Souttar and Brock were relieving mitral valve stenosis using finger or a dilator inserted in the left atrial appendage and the left ventricular apex $(1,2)$.

Cinching the posterior mitral valve annulus dimension from the outside on a beating heart to increase the leaflet coaptation height is intuitive and attractive. It utilizes landmarks in close proximity of the posterior mitral valve annulus. From the surgeon's view and the apex of the heart rotated rightwards and cephalad along the inferior margin of the coronary venous sinus between the posterior lateral artery and the posterior descending artery. This is because the posterior mitral valve annulus is few millimeters below the coronary sinus though this varies from patient to patient.

In the study published today by the Fournal of Thoracic Disease by Dr. Li et al. (3), the authors elegantly reported on 16 adult patients with mean age of 57 years with an epicardial pledgeted suture cinching the posterior mitral valve annulus at the time of their CABG for moderate ischemic mitral valve regurgitation and coronary artery disease. The procedure was performed off pump following coronary revascularization using an epicardial stabilizer to totally expose the PDA, coronary sinus and PLA pulling the apex of the left ventricle cephalad (see attached video). Thereafter the authors ran a continuous pledgeted suture (pericardial/felt enforced) in the fat pad cushion part of the ventricular muscle from the medial aspect PDA to the medial aspect of the PLA and the caudad to the coronary sinus. The suture was repeated again a few $\mathrm{mm}$ below the first and knotted to each other. They were able to reduce the degree of mitral regurgitation from $3.8 \mathrm{~mm}^{2}$ to average of $2.3 \mathrm{~mm}^{2}$ reporting good outcomes (3).

The advantages of this approach include avoidance of the coronary arteries, unnecessary opening of the left atrial cavity, minimize air entry into the heart and the time spent in removal of air from the heart. The disadvantages of this approach are obvious, the uncertainty in reaching the posterior mitral valve annulus to accurately and effectively reducing posterior mitral valve annulus, the lack of ascertaining the correct orientation and accurate depth of the needle, the lack of direct surgical valve assessment and tactile feedback of the quality and quantity of structures the needle traverses. Obviously, visualization under echocardiography preferably with 3D can be helpful and the authors demonstrated feasibility.

A novel and original study by Dr. Raman et al. adopted a similar approach on a population of ischemic heart disease with at least moderate mitral valve regurgitation (4). This cohort required coronary artery bypass with or without left ventricular reconstruction. Though the epicardial approach was similar, the technique utilizing an epicardial cardiac basal annuloplasty was novel. The technique uses hernia mesh placed along the atrioventricular groove extending to the anterior surface of the heart reducing the perimeter of the base "the waist "of the heart. The authors were able to 
reduce the mean gradient of mitral regurgitation (2.8 preand 0.3 post-surgery; $\mathrm{P}<0.05$ ).

The underpinning question that has been asked many times before is should we surgically intervene on moderate plus mitral regurgitation in the setting of surgical coronary artery revascularization. The data though supportive in some patients with symptoms of heart failure, the cumulative data suggests that fixing moderate mitral regurgitation does not alter overall survival but may improve quality of life $(5,6)$.

While it is highly likely that addressing the mitral valve at the time of the coronary artery revascularization can be done, there is a definite increased risk in morbidity and mortality when compared to coronary revascularization alone. The reasons for this excess burden on outcome are due to the reduced cardiac function tethering the mitral valve leaflets as well the prolonged surgery. The epicardial approach of reducing the posterior annulus would help in minimizing the extra time necessary to open the left atrium, repair or replace the mitral valve.

However, the reader needs to know that there is no survival advantage of repairing moderate mitral valve regurgitation at the time coronary revascularization $(5,6)$. Nonetheless, reducing the end diastolic volume can help in reducing the left atrial pressure and improve pulmonary return.

Additional techniques and advances in heart surgery do widen the platform of tackling the same problem from different perspectives. However, achieving the end result is influenced by effectiveness and simplicity in a safe and reproducible manner. Overachieving may not translate into reproducible safe effectiveness. Regarding the epicardial approach to reduce the posterior mitral valve annulus and degree of regurgitation, while this is innovative, it is not something most surgeons would be willing to learn and risk given the limitations however it is definitely worthy of knowing.

It is unclear where most of the techniques of surgical mitral valve repair will be in the next 10 years given the continued development and application of transcatheter mitral valve repair and replacement techniques (7). These techniques have targeted the annulus, leaflet and chords (8). They are ultimately the least invasive since there are no chest incision and if successful will be able to improve cardiac function without the need for cardiopulmonary bypass. The reason I mention this here is that while surgery remains the approach, we have known best to repair and replace the mitral valve, we as surgeons need to be open to learning, innovating and being part of developing new approaches and techniques

Sir Darwin stated "In science the credit goes to the man who convinces the world, not the man to whom the idea first occurs" (9). Reliable operative techniques requires good scientific explanation in addition to manual dexterity.

While there are so many ideas to fix the same problem, only a handful of novel ideas convinced by majority of practicing surgeons will enter mainstream practice.

The epicardial approach to the mitral valve will need to be performed by many surgeons and outcome follow up over a few years before it becomes widely accepted.

\section{Acknowledgments}

Funding: None.

\section{Footnote}

Conflicts of Interest: JS serves as the unpaid editorial board member of Journal of Thoracic Disease from Apr 2018 to Mar 2020. MN has no conflicts of interest to declare.

Ethical Statement: The authors are accountable for all aspects of the work in ensuring that questions related to the accuracy or integrity of any part of the work are appropriately investigated and resolved.

Open Access Statement: This is an Open Access article distributed in accordance with the Creative Commons Attribution-NonCommercial-NoDerivs 4.0 International License (CC BY-NC-ND 4.0), which permits the noncommercial replication and distribution of the article with the strict proviso that no changes or edits are made and the original work is properly cited (including links to both the formal publication through the relevant DOI and the license). See: https://creativecommons.org/licenses/by-nc-nd/4.0/.

\section{References}

1. Logan A, Turner R. Surgical treatment of mitral stenosis with particular reference to the use to the transventricular approach with a mechanical dilator. Lancet 1959;2:874-80.

2. Westaby S. Houston and oxford: a celebration of international fellowship. Tex Heart Inst J 2005;32:303-17.

3. Li J, Gu C. Off-pump mitral valve repair: primary result of treating moderate ischemic mitral regurgitation during off-pump coronary artery bypass grafting. J Thorac Dis 
2019;11:3191-4.

4. Raman J, Hare D, Storer M, et al. Epicardial cardiac basal annuloplasty: Preliminary findings on extra-cardiac mitral valve repair. Heart Lung Circ 2009;18:401-6.

5. Smith PK, Puskas JD, Ascheim DD, et al. Cardiothoracic Surgical Trials Network Investigators. Surgical treatment of moderate ischemic mitral regurgitation. N Engl J Med 2014;371:2178-88.

6. Michler RE, Smith PK, Parides MK, et al. Two-Year Outcomes of Surgical Treatment of Moderate Ischemic

Cite this article as: Shuhaiber J, Nores M. New approaches for mitral valve surgery without opening the left atrium. J Thorac Dis 2020;12(3):150-152. doi: 10.21037/jtd.2019.12.78
Mitral Regurgitation. N Engl J Med 2016;374:1932-41.

7. Flynn CD, Wilson-Smith AR, Yan TD. Novel mitral valve technologies-transcatheter mitral valve implantation: a systematic review. Ann Cardiothorac Surg 2018;7:716-23.

8. Sorajja P, Maisano F. Percutaneous Treatment for Native Mitral Regurgitation. Prog Cardiovasc Dis 2017;60:405-14.

9. Darwin SF. First Galton Lecture. Eugenics Review. London: Galton Institute, 1914:9. 